Sushchyk V. Characteristics of physical activity of men of the second period of mature age and their motivational orientation to practicing recreational swimming. Theory and Methods of Physical education and sports. 2019; 1: 84-88 DOI:10.32652/ tmfvs.2019.1.84-88
Сущик В. Характеристика фрізичної активності чоловіків другого періоду зрілого віку та їх мотиваційної спрямованості до занять оздоровчим плаванням. Теорія і методика фізичного виховання і спорту. 2019;1: 84-88 DOI:10.32652/tmfvs.2019.1.84-88

\title{
ХАРАКТЕРИСТИКА ФІЗИЧНОЇ АКТИВНОСТІ ЧОЛОВІКІВ ДРУГОГО ПЕРІОДУ ЗРІЛОГО ВІКУ ТА ЇХ МОТИВАЦІЙНОЇ СПРЯМОВАНОСТІ ДО ЗАНЯТЬ ОЗДОРОВЧИМ ПЛАВАННЯМ
}

\section{Володимир Сущик}

Національний університет фізичного виховання і спорту України, Київ, Україна

\begin{abstract}
Анотація. Фізична активність $є$ важливим компонентом здоров'я та довголіття чоловіків зрілого віку. В роботі було досліджено показники рівня рухової активності чоловіків 40-50 років та визначено мотиваційні пріоритети до занять оздоровчим плаванням. Проведено оцінку показників фрізичної активності чоловіків другого періоду зрілого віку ( $n=30$ ) за 7 днів (кількість днів) і час (години і хвилини) за спрощенню методикою міжнародного опитувальника IPAQ (International Physical Activity Questionnaire). Обчислено показники MET (metabolic equivalent of task). Визначено показники фрізичної активності в трьох зонах інтенсивності. Основну увагу було зосереджено на фрізичній роботі високої або помірної потужності, а також на енергетичних витратах на ходьбу і рівень фрізичної активності у вільний час. Мета. Вивчити показники рівня наукової активності чоловіків 40-50 років та рівень їхньої мотиваційної спрямованості до занять оздоровчим плаванням. Методи. Аналіз науково-методичної літератури, анкетування, педагогічні спостереження. Результати. У ході дослідження було розроблено анкету для характеристики самопочуття обстежуваних протягом дня, наприкінці робочого тижня та після тренування, було оцінено окремі суб'єктивні показники самопочуття, такі як сон, апетит, схильність до захворювань, ставлення до шкідливих звичок. У дослідженні мотивів до занять оздоровчим плаванням чоловіків другого періоду зрілого віку було виявлено, що пріоритетною є група під назвою «Здоров'я», на другому місиі з невеликим відривом зафріксовано групу мотивів «Красива фрігура», потім емоційний і соціальний мотиви. Підтверджено динаміку вікових змін інтенсивності фрізичної активності чоловіків другого періоду зрілого віку, що має тенденцію до зниження зі збільшенням віку респондентів. Дослідження мотивів до занять оздоровчим плаванням відіграє важливу роль у плануванні рухової активності чоловіків протягом всього періоду оздоровчих занять. Результати дослідження можуть бути використані під час розробки програм оптимізації фрізичної активності чоловіків 40-50 років інструкторами басейнів, тренерами фрітнес-клубів та в процесі самостійних фрізкультурно-оздоровчих занять. Подальші дослідження пов'язані із удосконаленням програми занять з оздоровчого плавання чоловіків зрілого віку другого періоду, що буде спрямована на підвищення рівня їхньої фрізичної активності і здоров'я.
\end{abstract}

Ключові слова: чоловіки другого періоду зрілого віку, фрізична активність, IPAQ, MET, мотивація, оздоровче плавання.

\section{Volodymyr Sushchyk \\ CHARACTERISTICS OF PHYSICAL ACTIVITY OF MEN OF THE SECOND PERIOD OF MATURE AGE AND THEIR MOTIVATIONAL ORIENTATION TO PRACTICING RECREATIONAL SWIMMING}

\begin{abstract}
Physical activity is an important component of the health and longevity of mature males. In this work, the indice of motor activity level of men aged 40-50 years were investigated and motivational priorities for practicing health related swimming were determined. The evaluation of the physical activity indices of men of the second period of adulthood ( $n=30)$ was made during 7 days (number of days) and time (hours and minutes) according to simplified method of the International Physical Activity Questionnaire (IPAQ). MET indices (metabolic equivalent of task) were calculated. The physical activity indices in three intensity zones were determined. The main focus was on the physical work of high or moderate power, as well as the energy expenditures during walking and the level of physical activity during free time. Objective. To study the indices of scientific activity level of men aged 40-50 years and their level of motivational orientation to practicing health related swimming. Methods. Analysis of scientific and methodological literature, questionnaires, pedagogical observations. Results. In the course of studies, a questionnaire was developed to describe the general state of the subjects during the day, at the end of the working week and after the workout. Some subjective indices of the general state, such as sleep, appetite, predisposition to illness, and attitude towards harmful habits were assessed. In the study of the motives for swimming engagement of men of the second period of mature age, it was found that the priority is a group called "Health», in the second place with a small margin, a group of motifs "Beautiful figure» was recorded, then emotional and social motives. The dynamics of age changes in the intensity of physical activity of men of the second period of mature age, which tends to decrease with increasing age of respondents, has been confirmed. Investigation of the motives for exercising recreational swimming plays an important role in the planning of motor activity of men throughout the whole period of recreational activities. The findings can be used to develop programs for optimizing the physical activity of men aged 40-50 years by
\end{abstract}


instructors of pools, coaches of fitness clubs as well as in the process of independent physical culture and recreation classes. Further research is related to the improvement of the program of recreational swimming for men of the mature age of the second period of the mature age, which will be aimed at increasing their physical activity and health.

Keywords: men of the second period of mature age, physical activity, IPAQ, MET, motivation, health related swimming.

Вступ. Сьогодні в нашій країні склалася критична ситуація зі станом здоров'я населення: близько 70 \% дорослих мають низький і нижчий за середній стан, зокрема у 40-59 років - 81,2 \% осіб. Захворюваність на гіпертонію, стенокардію, інфаркт міокарда зросла на 30 \%. При цьому зміцнення здоров'я передбачає використання засобів фізичної культури, які сприяють підвищенню стійкості організму до несприятливих умов зовнішнього середовища, до розумового напруження, стресових ситуацій, різних захворювань [4, 12].

Вплив оздоровчого плавання на організм людини вже давно визнано корисним, але і нині це є однією з найбільш актуальних проблем спортивної медицини, педагогіки, теорії та методики фізичного виховання. У багатьох дослідженнях виявлено, що регулярні заняття з плавання позитивно впливають на опорно-руховий апарат людини, його серцеву і дихальну системи, що запобігає розвитку дегенеративних змін, пов'язаних зі старінням і гіподинамією.

На особливу увагу заслуговують праці К. Г. Айрапетової [1], присвячені питанням корекції фізичного стану чоловіків другого зрілого віку в процесі фізкультурно-оздоровчих занять. Оздоровчу програму занять для чоловіків середнього віку на основі застосування вправ силової спрямованості в динамічному режимі запропоновано Д. Н. Карповим [5], О. Л. Благій [3] досліджено сучасні підходи до управління фізичним станом чоловіків зрілого віку в процесі кондиційного тренування з використанням засобів оздоровчого фітнесу, Е. Н. Чернишовою [13] розроблено підходи до організації фітнес-програм чоловіків зрілого віку з використанням тренажерних пристроїв в умовах фітнес-клубу.

Аналіз теоретичних напрацювань учених свідчить про зростання кількості досліджень, присвячених проблемі покращення фізичного стану чоловіків зрілого віку засобами оздоровчого плавання. Так, Л. В. Шейко [14] було визначено основні чинники, що впливають на вибір оздоровчого плавання на заняттях у групах здоров'я з чоловіками 50-60-літнього віку, розглянуто основні варіанти рухів ногами, що є визначальним фактором під час вибору способу оздоровчого плавання для цього контингенту. О. І. Алексєєв, В. М. Філь [2] представили методику оздоровчого плавання для здорових людей та людей, які мають патологічні зміни в опорно-руховому апараті (на прикладі деформуючого артрозу) і гіпертонічну хворобу першого і другого ступеня.

Вивчення наукової літератури [6-8, 10, 11] переконує, що поряд із загальноприйнятними методиками організації фізкультурно-оздоровчих за- нять багатьма дослідниками доведено позитивний вплив занять плаванням. Проте інформації, що відображає рівень фізичної активності чоловіків другого періоду зрілого віку, які висловили бажання займатися оздоровчим плаванням, у доступних нам джерелах виявилося вкрай мало. Все це зумовило актуальність теми дослідження.

Роботу виконано згідно зі Зведеним планом науково-дослідної роботи у сфері фізичної культури і спорту на 2016-2020 рр. Міністерства освіти і науки та Міністерства молоді і спорту України за темою 3.13 «Теоретико-методичні основи здоров'яформуючих технологій у процесі фізичного виховання різних груп населення» (номер держреєстрації 0116U001615), та за темою 3.15 «Теоретикометодологічні засади оздоровчо-рекреаційної рухової активності різних груп населення» (номер держреєстрації 0116U001630).

Мета дослідження - вивчити показники рівня рухової активності чоловіків 40-50 років та рівень їхньої мотиваційної спрямованості до занять оздоровчим плаванням.

Методи дослідження: аналіз науково-методичної літератури, анкетування, педагогічні спостереження, методи математичної статистики.

Результати дослідження та їх обговорення. Фізичну активність чоловіків другого періоду зрілого віку оцінювали за спрощеною методикою міжнародного опитувальника фізичної активності IPAQ (International Physical Activity Questionnaire) $[15,16]$.

Респондентам було запропоновано заповнити скорочену версію IPAQ, яка дозволяє отримати інформацію про час (години та хвилини) і кількість витраченої енергії (МЕТ) на фізичну активність різної інтенсивності за останні сім днів. Аналіз отриманих даних передбачав обчислення величини МЕТ - показник, який відображає енергоспоживання під час фізичної роботи, де 1 MET дорівнює швидкості метаболізму під час споживання 3,5 млл $\cdot 1$ кг $^{-1} \cdot \mathrm{xв}^{-1}$, що аналогічно використанню 1 ккал · 1 кг $\cdot 1$ год [9, 15].

В опитуванні брали участь 30 чоловіків 4050 років $(\mathrm{n}=30)$, які виявили бажання займатись оздоровчим плаванням. Тестування було проведене до початку занять оздоровчим плаванням у спорткомплексах м. Києва.

Фізично неактивними чоловіками вважали тих, хто відповів, що він більшу частину часу проводить на роботі сидячи або зовсім не працює, при цьому ходить менше 30 хв на день і зовсім не займається фізичною активністю (ФА) у вільний від роботи час. Низький рівень ФА мали особи, які відповіли, що вони більшу частину часу проводять на роботі сидячи або не працюють, при цьому хо- 
Таблиця 1 - Фізична активність чоловіків другого періоду зрілого віку $(\mathrm{n}=30)$

\begin{tabular}{|c|c|c|c|}
\hline Показник & Фізична активність & $\begin{array}{c}\text { MET, хв - тиж., } \\
\text { M } \pm \text { SE }\end{array}$ & $\begin{array}{c}\text { Загаль- } \\
\text { на } \\
\text { ФА, \% }\end{array}$ \\
\hline \multirow[t]{3}{*}{ Робота } & ходьба & $2466 \pm 314$ & 14,4 \\
\hline & $\begin{array}{l}\text { робота середньої по- } \\
\text { тужності }\end{array}$ & $2396 \pm 345$ & 13,3 \\
\hline & $\begin{array}{l}\text { робота високої потуж- } \\
\text { ності }\end{array}$ & $4900 \pm 630$ & 17,6 \\
\hline \multirow{2}{*}{$\begin{array}{l}\text { Перемі- } \\
\text { щення }\end{array}$} & ходьба & $1689 \pm 365$ & 6,9 \\
\hline & їзда на велосипеді & $206 \pm 143$ & 1,8 \\
\hline \multirow{2}{*}{$\begin{array}{l}\text { Робо- } \\
\text { та вдома } \\
\text { (госпо- } \\
\text { дарство) }\end{array}$} & $\begin{array}{l}\text { робота високої потуж- } \\
\text { ності }\end{array}$ & $3126 \pm 465$ & 17,1 \\
\hline & $\begin{array}{l}\text { робота середньої по- } \\
\text { тужності }\end{array}$ & $3168 \pm 361$ & 15,3 \\
\hline \multirow[t]{3}{*}{ Дозвілля } & ходьба & $403 \pm 79$ & 3,1 \\
\hline & $\begin{array}{l}\text { робота середньої по- } \\
\text { тужності }\end{array}$ & $804 \pm 203$ & 6,4 \\
\hline & $\begin{array}{l}\text { робота високої потуж- } \\
\text { ності }\end{array}$ & $1401 \pm 235$ & 4,1 \\
\hline
\end{tabular}

дять пішки 30-60 хв на день і не займаються фізичною активністю у вільний від роботи час. Середній рівень ФА припускав піднімання і перенесення невеликих вантажів на роботі або ходьбу пішки від 60 до 90 хв на день, так само наявність ФА у вільний від роботи час від одного до чотирьох днів на тиждень. Високий рівень ФА мали респонденти, які відповіли, що вони займаються важкою фізичною роботою або ходять від 90 хв і більше на день або займаються ФА у вільний від роботи час п'ять і більше днів на тиждень. Результати опитування представлено в таблиці 1.

Основна увага була зосереджена на ФА високої або помірної потужності та на енергетичних витратах на ходьбу.

На виконання роботи високої потужності чоловіки 40-50 років витрачають 15-40\% загальної кількості MET, найнижчим це співвідношення є у чоловіків $з$ нормальною масою тіла. Щодо інших різновидів роботи та ФА, суттєвих відмінностей у цього контингенту не виявлено. На ФА у вільний час використовують 7-14 \% загальної кількості MET-хв · тиж., на ходьбу пішки - 22-29\%, роботу середньої потужності - 40-49\%. Так, у вільний час на роботу середньої і значної потужності у чоловіків другого періоду зрілого віку припадає 322-804 МЕТ-хв · тиж., але такий рівень ФА абсолютно недостатній для поліпшення та збереження Здоров'я.

3 метою з'ясування мотивів до занять оздоровчим плаванням чоловіків 40-50 років ми провели анкетування, в ході якого було опитано 30 чоловіків, які склали основну групу.

Аналіз отриманих результатів показав, що у чоловіків другого періоду зрілого віку пріоритетною є група мотивів під назвою «Здоров'я» $(56,4$ \%).
На другому місці з невеликим відривом зафіксовано групу мотивів «Красива фігура» $(34,2 \%)$, потім емоційний $(7 \%)$ і соціальний $(2,4 \%)$ мотиви.

У ході нашого дослідження було розроблено анкету, яка включала 10 запитань, спрямованих на визначення самопочуття обстежуваних протягом дня, наприкінці робочого тижня та після тренування, окремі суб'єктивні показники самопочуття, такі як сон, апетит, схильність до захворювань, ставлення до шкідливих звичок, ступінь задоволення від занять. Відповіді на поставлені запитання оцінювали від 1 до 3-4 балів, а в окремих випадках - до 5 балів. При цьому градація шкали коливалась у межах від 10 балів у найкращому випадку, до 30 балів - у найгіршому. На основі проведено анкетування було встановлено, що середній бал, який у обстежуваних варіював від 18 до 22 , становив 20,23 ( $\mathrm{S}=1,87)$. Виявлено, що самопочуття протягом дня 47,6 \% чоловіків оцінили як незадовільне, 53,4 \% - добре, і жоден з опитуваних не оцінив його як дуже добре; наприкінці робочого тижня почуваються дуже втомленими $56,7 \%, 43,3 \%$ - втомленими і жоден не почувався бадьорим; 70 \% чоловіків зізнались, що у них трапляються розлади сну й апетиту, при цьому тільки 16,67 \% взагалі не мають шкідливих звичок і лише $20 \%$ задоволені своєю статурою.

Висновки. Досліджувана фізична активність чоловіків другого періоду зрілого віку відповідає середньому рівню, за рекомендаціями ВОЗ, i має тенденцією до зниження 3 віком, також кількість занять із середньою та високою інтенсивністю суттєво зменшується. Чоловіки цього віку присвячують найбільше часу на заняття фізичною активністю низької інтенсивності щодня, що можна пояснити виробленими звичками, пов'язаними 3 робочими, сімейними, побутовими традиціями. Встановлено, що чоловіки 40-50 років переважно мають низьку фізичну активність, що абсолютно недостатньо для поліпшення та збереження здоров'я.

Слід зауважити, що результати проведеного анкетування підтвердили загальну тенденцію нехтування засадами здорового способу життя чоловіками другого періоду зрілого віку, що веде до раннього старіння, яке проявляється у зниженні працездатності, розладах сну й апетиту, а також викликає відчуття втоми і незадоволення.

Перспективи подалыших досліджень полягають у подальшому дослідженні, розробці й обгрунтуванні програми оздоровчого плавання для підвищення рівня фізичного стану чоловіків другого періоду зрілого віку. Використання індивідуального підходу та комплексу фізкультурнооздоровчих засобів у систематичних заняттях фізичним вправами дозволить позитивно впливати на їхню мотиваційну сферу, фізичний стан та формування потреби підвищення рухової активності зазначеного контингенту.

Конфлікти інтересів. Автор заявляє, що відсутній будь-який конфлікт інтересів. 


\section{Література}

1. Айрапетова КГ. Коррекция физического состояния мужчин второго зрелого возраста в процессе физкультурнооздоровительных занятий [автореферат]. Киев, 1997. 24 с.

2. Алєксєєв ОІ, Філь ВМ. Оздоровче плавання як засіб реабілітації для людей середнього і старшого віку. Медична гідрологія та реабілітація. 2008; 6 (2): 38-45.

3. Благій О. Сучасні підходи до управління фрізичним станом чоловіків зрілого віку в процесі кондиційного тренування. Теорія і методика фріз. виховання і спорту. 2015; 1: 22-25.

4. Голованов СА. Комплексная коррекция здоровья мужчин в условиях аэробных фризических нагрузок [диссертация]. Москва; 2015. 183 с.

5. Карпов ДН. Оздоровительная физическая культура мужчин среднего возраста на основе применения упражнений силовой направленности в динамическом режиме [диссертация]. Москва; 2010. 142 с.

6. Кашуба ВО, Гончарова НМ. Сучасні підходи до моніторингу фрізичного стану школярів у процесі фрізичного виховання. В: СС. Єрмаков, редактор. Педагогіка, психологія та мед.-біол. пробл. фріз. виховання і спорту. Зб. наук. пр. Харків : ХДФДМ (ХХПІ). 2010; 1: 71-73.

7. Кашуба В, Гончарова Н, Дудко М, Мартинюк О. До питання підвищення ефективності фрізкультурно-оздоровчих занять різних груп населення. В: АВ. Цьось, АІ. Альошина, укладачі. Молодіж. наук. вісн. Східноєвроп. нац. ун-ту ім. Лесі Українки. Фізичне виховання і спорт. Луцьк. 2016; 24: 9-14.

8. Кашуба В, Алешина А, Прилуцкая Т, Руденко Ю, Лазько О, Хабинец Т. К вопросу использования современных занятий профилактико-оздоровительной направленности с людьми зрелого возраста. В: АВ. Цьось, АІ. Альошина. Молодіж. наук. вісн. Східноєвроп. нац. ун-ту ім. Лесі Українки. Луцьк. 2018, 29: 50-59.

9. Протокол и практическое руководство. Общенациональная интегрированная программа профилактики неинфекционных заболеваний (CINDI) (пересмотр 1994 г.). Копенгаген: ВОЗ/ЕРБ. 1996.

10. Ріпак I. Педагогічні шляхи підвищення обсягів та вдосконалення змісту рухової активності чоловіків 30-40 років, зайнятих розумовою працею. Молода спорт. наука України. 2003; 2 (7): 389-392.

11. Строганов СВ. Корекція статури чоловіків першого зрілого віку засобами оздоровчого фрітнесу. В: СС. Єрмаков, редактор. Педагогіка, психологія та мед.-біол. пробл. фріз. виховання і спорту. 3б. наук. пр. Харків. 2010: $112-114$.

12. Футорний СМ. Теоретико-методичні основи інноваційних технологій фрормування здорового способу життя студентів в процесі фрізичного виховання [автореферат]. Київ, 2015. 43 с.

13. Чернышева EH. Организация двигательной активности мужчин зрелого возраста средствами атлетической гимнастики. Учен. зап. ун-та им. П. Ф. Лесгафтта. 2012; 8 (90): 106-109.

14. Шейко ЛВ. Выбор способа для освоения оптимальной дистанции оздоровительного плавания мужчинами 51-60 лет. Слобожан. наук.-спорт. вісн. 2012; 1: 18-21.

15. Bull FC, Maslin TS, Armstrong T. Global physical activity questionnaire (GPAQ): nine country reliability and validity study. J Phys Act Health. 2009;6(6):790-804.

16. The International Physical Activity Questionnaire, 2005. Available at http://www.ipaq.ki.se/ [Elektronik resourse]. Mode of access : http://www.who.int/dietphysicalactivity/ factsheet_recommendations/en/

\section{Literature}

1. Ayrapetova KG. Correcting physical state of men of the second mature age in the process of physical culture and health related sessions [author's abstract]. Kiev, 1997. 24 p.

2. Alekseiev OI, Fil VM. Health related swimming as a rehabilitation means for persons of middle and old ages. Medychna hidrolohiia ta reabilitatsiia. 2008; 6 (2): 38-45.

3. Blahii O. Modern approaches to managing physical state of mature age men during conditioning training. Teoriia $\mathrm{i}$ metodyka fizvykhovannia i sportu. 2015; 1: 22-25.

4. Golovanov SA. Complex correction of male health under conditions of aerobic physical loads [ dissertation]. Moscow; 2015. 183 p.

5. Karpov DN. Health related physical culture of middle age men on the basis of applying strength exercises in dynamic mode [dissertation]. Moscow; 2010. 142 p.

6. Kashuba VO, Honcharova NM. Modern approaches to monitoring physical state of school children during physical education. In: SS. lermakov, editor. Pedahohika, psykholohiia ta med.-biolohichni problem fizvykhovannia i sportu. Kharkiv: KDFDM (XXПI). 2010; 1: 71-73.

7. Kashuba B, Honcharova N, Dudko M, Martyniuk O. On issue of improving efficiency of physical culture and health related sessions for different population groups. In: AV. Tsos, Al. Alioshyna, compilers. Molodizhnyi naukovyi visnyk Skhidnoievropeyskoho universytetu imeni Lesi Ukrainky. Lutsk. 2016; 24: 9-14.

8. Kashuba B, Aleshina A, Prilutskaya T, Rudenko Y, Kazko O, Khabinets T. On usage of modern sessions of preventivehealth related direction for aged people. In: AV. Tsos, Al. Alioshyna, compilers.. Molodizhnyi naukovyi visnyk Skhidnoievropeyskoho universytetu imeni Lesi Ukrainky. Lutsk. 2018, 29: 50-59.

9. Protocol and practical guide. General national integrated program for non-infectious disease (CINDI) prevention (CINDI) (revised in 1994). Kopengagen: VOZ/ERB. 1996. 
10. Ripak I. Pedagogical ways of enhancing the content of motor activity in men aged 30-40 years engaged in intellectual activity. Moloda sportyvna nauka Ukrainy. 2003; 2 (7): 389-392.

11. Strohanov SV. Correcting posture of men of the first mature age by means of health related fitness. In: SS. Iermakov, editor. Pedahohika, psykholohiia ta med.-biolohichni problem fizvykhovannia i sportu. Kharkiv. - 2010: 112-114.

12. Futornyi SM. Theoretico-methodical bases of innovation technologies for healthy life style formation in students during physical education [author's abstract]. Kyiv, 2015. 43 p.

13. Chernysheva EN. Motor activity organization for mature age men by means of athletic gymnastics. Uchenyye zapiski universiteta imeni P. F. Lesgafta. 2012; 8 (90): 106-109.

14. Sheyko LV. Selection of method for mastering optimum distance of health related swimming by men aged 51-60 years. Slobozhanskyi naukovo-sportyvnyi visnyk. 2012; 1: 18-21.

15. Bull FC, Maslin TS, Armstrong T. Global physical activity questionnaire (GPAQ): nine country reliability and validity study. J Phys Act Health. 2009;6(6):790-804.

16. The International Physical Activity Questionnaire, 2005. Available at http://www.ipaq.ki.se/ [Elektronik resourse]. Mode of access : http://www.who.int/dietphysicalactivity/ factsheet_recommendations/en/

Надійшла 20.02.2019

\section{Інформація про авторів}

Сущик Володимир Феліксович

https://orcid.org/0000-0002-6622-6294

volodymyrsushchyk@gmail.com

Національний університет фрізичного виховання і спорту України, 03150, Київ, вул. Фізкультури, 1
About the authors

Sushchyk Volodymyr https://orcid.org/0000-0002-6622-6294 volodymyrsushchyk@gmail.com

National University of Ukraine on Physical Education and Sport, 03150, Kyiv, 1, Fizkultury St. 